\title{
Use of intra-aortic balloon pump in cardiac surgery: analysis of 80 consecutive cases
}

\author{
Uso do balão intra-aórtico no trans e pós-operatório de cirurgia cardíaca: análise de 80 casos \\ consecutivos
}

\author{
Fernando Pivatto Júnior ${ }^{1}$, Ana Paula Tagliari ${ }^{1}$, Anderlise Bard Luvizetto ${ }^{2}$, Edemar Manuel Costa \\ Pereira $^{3}$, Erci Maria Onzi Siliprandi ${ }^{4}$, Ivo Abrahão Nesralla ${ }^{5}$, Rodrigo Pires dos Santos ${ }^{6}$, Renato \\ Abdala Karam Kalil ${ }^{7}$
}

DOI: $10.5935 / 1678-9741.20120041$

RBCCV 44205-1378

\section{Abstract}

Background: The low cardiac output syndrome in perioperative period of cardiac surgery may occur in about 10 to $15 \%$ of patients; of this total, $2 \%$ require mechanical support for adequate hemodynamic control.

Objective: This study aimed to describe the mortality of patients requiring intra-aortic balloon pump (IABP) in transor post-cardiac surgery, identifying preoperative variables associated with a worse outcome, as well as describe the postoperative complications and survival in the medium term. Patients and Methods: retrospective cohort study including 80 consecutive cases between January/2009 and September/ 2011. The patients had on average $62.9 \pm 11.3$ years and $58.8 \%$ were male. In the sample, $81.3 \%$ were hypertensive, $50 \%$ had previous myocardial infarction and $38.8 \%$ heart failure NYHA III/IV. The most common surgery performed was isolated coronary artery bypass grafting $\mathbf{( 3 7 . 5 \% )}$.

Results: Hospital mortality was $53.8 \%$ (95\% HF: 42.764.9) and the cross-clamp time $>90$ minutes was an independent predictor of mortality in multivariate analysis (RR 1.52 95\% HF: 1.04-2.22). Regarding complications, $71.3 \%(95 \%$ HF: 61.2 to 81.4$)$ of patients had at least one additional complication: the lower limb ischemia was

1. Graduation in Medicine - Institute of Cardiology of Rio Grande do Sul / University Foundation of Cardiology (IC / FUC), Porto Alegre, Brazil.

2. Technical nursing of IC / FUC, Porto Alegre, Brazil.

3. Specialist in Cardiology and Intensive Care - IC / FUC and the Federal University of Health Sciences of Porto Alegre (UFCSPA), Porto Alegre, Brazil.

4. Degree in Nursing - IC / FUC, Porto Alegre, Brazil.

5. PhD - IC / FUC, Porto Alegre, Brazil.

6. Postdoctoral - IC / FUC, Porto Alegre, Brazil.

7. PhD - IC / FUC and the Federal University of Health Sciences of Porto Alegre (UFCSPA), Porto Alegre, Brazil. observed in $5.0 \%$ of patients. The 1-year survival was $43.6 \%$, observing a plateau in the survival rate after an initial sharp drop, related to hospital mortality.

Conclusion: Patients who need the IABP form a group of very high risk for morbidity and mortality. Its use, however, allows many patients to recover an evolution that was invariably fatal, having the patients discharged home a good survival in the medium term.

Descriptors: Intra-aortic balloon pumping. Cardiac surgical procedures. Cardiac output, low.

\section{Resumo}

Fundamento: A síndrome de baixo débito cardíaco no perioperatório de cirurgia cardíaca pode incidir em cerca de 10 a $15 \%$ dos pacientes; desse total, $2 \%$ necessitam de suporte mecânico para adequado controle hemodinâmico.

Objetivos: Descrever a mortalidade de pacientes que necessitaram utilizar balão intra-aórtico (BIAo) no trans ou pós-operatório de cirurgia cardíaca, identificando variáveis pré-operatórias associadas a pior desfecho, assim como descrever as complicações pós-operatórias e a sobrevida em médio prazo.
Study conducted at the Institute of Cardiology of Rio Grande do Sul / University Foundation of Cardiology (IC / FUC), Porto Alegre, Brazil.

Correspondence Address:

Avenida Princesa Isabel, 370 - Santana - Porto Alegre, RS, Brazil Zip code: 90620-000

E-mail: fpivatto@gmail.com 


\begin{tabular}{|ll|}
\hline Abbreviations, & acronyms \& symbols \\
\hline IABP & Intra-aortic balloon pump \\
CPB & Cardiopulmonary bypass \\
CABG & Coronary Artery Bypass Graft Surgery \\
LVEF & Left ventricle ejection fraction \\
AMI & Acute myocardial infarction \\
HF & Heart failure \\
IC/FUC & Institute of Cardiology of Rio Grande do Sul / \\
& FUC \\
ARF & Acute renal failure \\
NYHA & New York Heart Association \\
CPA & Cardiopulmonary arrest \\
LCA & Left main coronary artery \\
VAD & Ventricular assist devices \\
LV & Left ventricle \\
\hline
\end{tabular}

Métodos: Estudo de coorte retrospectivo incluindo 80 casos consecutivos entre janeiro/2009 e setembro/2011. Os pacientes possuíam, em média, $62,9 \pm 11,3$ anos e $58,8 \%$ eram do sexo masculino. Na amostra, $81,3 \%$ dos pacientes eram hipertensos, $50 \%$ tinham infarto do miocárdio prévio e $38,8 \%$, insuficiência cardíaca NYHA III/IV. A principal cirurgia realizada foi a revascularização miocárdica isolada $(37,5 \%)$.

Resultados: A mortalidade hospitalar nesta série foi de 53,8\% (IC95\%: 42,7-64,9), sendo o tempo de isquemia $\geq 90$ minutos preditor independente de mortalidade em análise multivariada (RR 1,52 IC95\%: 1,04-2,22). Em relação às complicações, 71,3\% (IC95\%: 61,2-81,4) dos pacientes apresentaram ao menos uma complicação adicional no período perioperatório, sendo a isquemia do membro inferior observada em $5 \%$ dos pacientes. A sobrevida em 1 ano foi de $43,6 \%$, observando-se um platô na curva de sobrevida após uma queda acentuada inicial, relacionada à mortalidade hospitalar.

Conclusões: Os pacientes que necessitam do BIAo compõem um grupo de muito alto risco para morbidade e mortalidade; seu emprego, entretanto, permite recuperar muitos pacientes de uma evolução que seria invariavelmente fatal, tendo os pacientes com alta hospitalar uma boa sobrevida em médio prazo.

Descritores: Balão intra-aórtico. Procedimentos cirúrgicos cardíacos. Baixo débito cardíaco.

\section{INTRODUCTION}

The results of cardiac surgical procedures continue to improve despite the increasing number of patients older and sicker. Many deaths are linked to complications related to low cardiac output during the perioperative period [1].

The low cardiac output syndrome in the perioperative period of cardiac surgery is defined as the need for inotropic support for more than 30 minutes in the intensive care unit or intra-aortic balloon pump (IABP) in the postoperative period, associated with a significant increase in morbidity and mortality [2]. This syndrome after cardiac surgery can focus on about 10 to $15 \%$ of patients; this total, $2 \%$ require mechanical support for appropriate hemodynamic control. The main reasons stand out hypovolemia, cardiac tamponade, right ventricular dysfunction, left ventricular failure consequent to poor myocardial protection and / or perioperative myocardial infarction. The hospital mortality of patients with low cardiac output syndrome is high, being the most common cause left ventricular failure secondary to acute myocardial infarction [3].

The use of mechanical support in cardiogenic shock had its beginning in models of open heart surgery, where failures occurred on withdrawal of the heart-lung bypass, in the years 1950-1960. The development of the mechanism of aortic counter-pulsation has its first records in the early years of the 1950s, however, the biggest success story occurred in 1969, with publication of Kantrowitz et al. [4] and is still commonly used connected directly to surgical treatment, because its mode of implantation is also made so that limited and hampered its routine use. From the year 1980, there was significant gain in scientific knowledge, combined with important technical industrial investment, with development of the delivery system through the femoral artery puncture with sheath and dilator [5], universalizing the use of IABP in various hospital environments, associating with it a great development of control mechanisms, which today have become almost selfadjusting [6].

The IABP is currently the device most widely used circulatory support in cardiac surgery, to result in a supply / demand ratio more favorable to heart failure [7]. \ In the U.S. alone, more than 70,000 patients annually receive hemodynamic support this device. The main indication of 
use in cardiac surgery is the use in the treatment of perioperative low cardiac output refractory to inotropic support usual [8].

The growing need of the use of the IABP during cardiac surgery in recent years has been reported by many centers, this is mainly due to the fact that the patient population has changed and now includes older patients with multivessel disease and a greater degree of dysfunction ventricular. On the other hand, there is a lower threshold for the use of this device, due to improved technology and relatively low complication rate [8].

This study has as main objective to describe the mortality of patients who required the use of the IABP in trans- or post-cardiac surgery at the Institute of Cardiology of Rio Grande do Sul / FUC (IC / FUC) and identify preoperative variables associated with worse outcome. Secondarily, it aims to describe the postoperative complications and survival in the medium term this patient population.

\section{METHODS}

A retrospective cohort study including all patients who required the use of the IABP in trans or post-cardiac surgery in the IC / FUC, from January/2009 to September/2011, due to difficulty in removing the cardiopulmonary bypass or cardiogenic shock refractory to vasoactive drugs.

The classification of heart failure (HF) was performed according to criteria established by the New York Heart Association (NYHA). Lesions of the left main coronary artery (LCA) was considered severe if greater than $50 \%$. The presence of renal preoperative was defined in presence of serum creatinine of more than $2 \mathrm{mg} / \mathrm{dl}$. Acute myocardial infarction (AMI) was considered recent if it occurred in the last 30 days. Current smoking was defined as smoking one cigarette in the last month. The diagnosis of lower limb ischemia was performed with a clinical basis. The mechanical ventilation time was considered prolonged if greater than 48 hours. The ischemia time was considered prolonged if greater than or equal to 90 minutes and cardiopulmonary bypass (CPB) is greater than or equal to 120 minutes. Hospital mortality was defined as the occurrence of death during hospitalization of the patient, regardless of its duration.

Patients were evaluated by consulting the records and the Mortality Information System of the State Health Secretariat of Rio Grande do Sul. Patients whose follow-up was lost were censored and were included in the survival analysis up to the date of the last day of hospitalization or outpatient visit last performed.

Data were collected from medical records retrospectively, being entered and analyzed with SPSS 15.0. The descriptive analysis for qualitative variables was performed from the distribution of absolute and relative frequency, and for quantitative, as the mean and standard deviation. In order to statistically assess the association between two qualitative variables, we used the chi-square or Fisher exact test when indicated. To evaluate the association between mortality risk and the variables we used Poisson regression with robust adjustment for variances, a method also used in the multivariate analysis, which included all variables with $\mathrm{P}<0.05$ in univariate analysis. The description of survival was performed by Kaplan-Meier method. The confidence interval of $95 \%$ was calculated when it saw fit, as shown in parentheses. The level of significance for all tests was $5 \%$.

This study was registered at the Research Unit of IC / FUC under number 4104/07 was approved by the local Research Ethics, on February 20, 2008.

Table 1. Preoperative characteristics of the sample.

\begin{tabular}{lc}
\hline Variable & $\mathrm{n}=80$ \\
\hline Age ( \pm dp) & $62,9 \pm 11,3$ \\
Male (\%) & $47(58,8)$ \\
Hypertension (\%) & $65(81,3)$ \\
Previous AMI (\%) & $40(50,0)$ \\
Recent AMI (\%) & $10(12,5)$ \\
IC NYHA III/IV (\%) & $31(38,8)$ \\
LVEF 30-50\% (\%) & $28(35,0)$ \\
LVEF < 30\% (\%) & $13(16,3)$ \\
Previous smoking (\%) & $26(32,5)$ \\
Current smoking (\%) & $15(18,8)$ \\
Diabetes (\%) & $25(31,3)$ \\
Severe lesion of LCA (\%) & $13(16,3)$ \\
Renal dysfunction (\%) & $8(10,0)$ \\
\hline
\end{tabular}

AMI: acute myocardial infarction, HF NYHA: classification of heart failure New York Heart Association, LVEF: left ventricular ejection fraction, LCA: left main coronary artery

Table 2. Surgical data.

\begin{tabular}{lc}
\hline Variable & $\mathrm{n}=80$ \\
\hline Urgency of operation & \\
Elective $(\%)$ & $55(68.8)$ \\
Urgency/Emergency $(\%)$ & $25(31.2)$ \\
Surgeries performed & \\
CABG alone $(\%)$ & $30(37.5)$ \\
Aortic valve replacement $(\%)$ & $8(10.0)$ \\
Mitral valve replacement $(\%)$ & $5(6.3)$ \\
CABG + Aortic valve replacement $(\%)$ & $5(6.3)$ \\
Ventriculoseptoplasty (\%) & $4(5.0)$ \\
CABG + LV aneurysm Correction $(\%)$ & $4(5.0)$ \\
CABG + Mitral valve replacement $(\%)$ & $3(3.8)$ \\
Aortic + mitral valve replacement $(\%)$ & $2(2.5)$ \\
Heart transplantation $(\%)$ & $2(2.5)$ \\
Mitral valve replacement + tricuspid valve plasty $(\%)$ & $2(2.5)$ \\
Other procedures $(\%)$ & $15(18.8)$ \\
Operative times & \\
Ischemia $( \pm$ sd) & $81.6 \pm 33.5$ \\
CPB $( \pm$ sd) & $127.5 \pm 54.0$ \\
Ischemia $\geq 90$ min $(\%)$ & $28(35.0)$ \\
CPB $\geq 120$ min $(\%)$ & $40(50.0)$ \\
\hline$C A B G:$ coronary artery bypass &
\end{tabular}

CABG: coronary artery bypass grafting, $L V$ : left ventricle, $C P B$ : cardiopulmonary bypass 


\section{RESULTS}

During the study period, 89 patients required the use of the IABP, nine $(10.1 \%)$ in the preoperative period, $39(43.8 \%)$ in the trans-operative, due to difficulty in weaning from $\mathrm{CPB}$, and $41(46.1 \%)$ in postoperative cardiogenic shock refractory to inotropic therapy, these last two groups, as already mentioned, objective analysis of this study.

Table 3. Univariate analysis of variables associated with mortality.

\begin{tabular}{|c|c|c|c|c|c|}
\hline \multirow{2}{*}{$\begin{array}{l}\text { Variable } \\
\text { Age } \geq 65 \text { years }\end{array}$} & \multicolumn{2}{|c|}{$\mathrm{n}=80$} & \multirow{2}{*}{$\begin{array}{c}\text { \% Mortalidade } \\
55.0\end{array}$} & \multirow{2}{*}{$\begin{array}{c}\text { RR (IC 95\%) } \\
1.05(0.70-1.57)\end{array}$} & \multirow{2}{*}{$\begin{array}{c}P \\
1.000\end{array}$} \\
\hline & Yes & 40 & & & \\
\hline & No & 40 & 52.5 & & \\
\hline \multirow[t]{2}{*}{ Male } & Yes & 47 & 59.6 & $1.31(0.84-2.04)$ & 0.308 \\
\hline & No & 33 & 45.5 & & \\
\hline \multirow[t]{2}{*}{ Hypertension } & Yes & 65 & 55.4 & $1.19(0.67-2.13)$ & 0.747 \\
\hline & No & 15 & 46.7 & & \\
\hline \multirow[t]{2}{*}{ Diabetes } & Yes & 25 & 48.0 & $0.85(0.53-1.36)$ & 0.650 \\
\hline & No & 55 & 56.4 & & \\
\hline \multirow[t]{2}{*}{ Active smoking } & Yes & 15 & 53.3 & $0.99(0.59-1.67)$ & 1.000 \\
\hline & No & 65 & 53.8 & & \\
\hline \multirow[t]{2}{*}{ Previous smoking } & Yes & 26 & 42.3 & $0.71(0.43-1.18)$ & 0.236 \\
\hline & No & 54 & 59.3 & & \\
\hline \multirow[t]{2}{*}{ HF NYHA III/IV } & Yes & 31 & 71.0 & $1.66(1.12-2.46)$ & 0.026 \\
\hline & No & 49 & 42.9 & & \\
\hline \multirow[t]{2}{*}{ Previous AMI } & Yes & 40 & 42.5 & $0.65(0.43-1.00)$ & 0.073 \\
\hline & No & 40 & 65.0 & & \\
\hline \multirow[t]{2}{*}{ Recent AMI } & Yes & 10 & 50.0 & $0.92(0.48-1.77)$ & 1.000 \\
\hline & No & 70 & 54.3 & & \\
\hline \multirow[t]{2}{*}{ LVEF $30-50 \%$} & Yes & 28 & 57.1 & $1.09(0.72-1.67)$ & 0.861 \\
\hline & No & 46 & 52.2 & & \\
\hline \multirow[t]{2}{*}{ LVEF < 30\% } & Yes & 13 & 46.2 & $0.83(0.44-1.55)$ & 0.747 \\
\hline & No & 61 & 55.7 & & \\
\hline \multirow[t]{2}{*}{ Severe lesion of LCA } & Yes & 13 & 46.2 & $0.80(0.43-1.50)$ & 0.666 \\
\hline & No & 61 & 57.4 & & \\
\hline \multirow[t]{2}{*}{ Renal dysfunction } & Yes & 8 & 62.5 & $1.18(0.66-2.11)$ & $0.71 \mathrm{c}$ \\
\hline & No & 72 & 52.8 & & \\
\hline \multirow[t]{2}{*}{ Non-elective surgery } & Yes & 25 & 64.0 & $1.30(0.87-1.94)$ & 0.318 \\
\hline & No & 55 & 49.1 & & \\
\hline \multirow[t]{2}{*}{ CABG alone } & Yes & 30 & 30.0 & $0.44(0.25-0.79)$ & 0.002 \\
\hline & No & 50 & 68.0 & & \\
\hline \multirow[t]{2}{*}{ Ischemic time $\geq 90 \mathrm{~min}$} & Yes & 28 & 71.4 & $1.61(1.10-2.37)$ & 0.036 \\
\hline & No & 52 & 44.2 & & \\
\hline \multirow{2}{*}{$\mathrm{CPB}$ time $\geq 120 \mathrm{~min}$} & Yes & 40 & 67.5 & $1.69(1.09-2.61)$ & 0.025 \\
\hline & No & 40 & 40.0 & & \\
\hline \multirow[t]{2}{*}{ Indication } & Trans & 39 & 51.3 & $0.91(0.61-1.37)$ & 0.836 \\
\hline & Post & 41 & 56.1 & & \\
\hline
\end{tabular}

AMI: acute myocardial infarction, HF NYHA: classification of heart failure New York Heart Association, LVEF: left ventricular ejection, TEC: left main coronary artery, CABG: coronary artery bypass grafting, CPB: cardiopulmonary bypass 
The sample was therefore 80 patients, about $3.3 \%$ of the patients in the period. The mean age was $62.9 \pm 11.3$ years, $40(50 \%)$ aged greater than or equal to 65 years. The preoperative characteristics of the sample are described in Table 1.

During the study period, $2.1 \%$ of all coronary artery bypass grafting $(\mathrm{CABG})$ performed alone required the use of the IABP in trans or post-operative, which constitutes a major surgical procedure performed in this series of cases (37.5\%.) Table 2 describes the surgeries, as well as the degree of urgency and the operative times, noting that $31.2 \%$ of the surgeries were elective and non-surgical times were prolonged ischemia and CPB in 35\% and 50\% of patients, respectively, and all procedures performed with CPB.

The hospital mortality rate was $53.8 \%$ (95\% HF: 42.7 to 64.9). In univariate analysis (Table 3), heart failure NYHA III / IV, surgery and non-CABG prolonged surgical times were associated with higher mortality a statistically significant manner. In the multivariate analysis (Table 4),

Table 4. Multivariate analysis of the association of variables with mortality.

\begin{tabular}{lcc}
\hline Variable & $\mathrm{RR}^{*}(\mathrm{IC} 95 \%)$ & $\mathrm{P} *$ \\
\hline HF NYHA III/IV & $1.49(1.00-1.23)$ & 0.050 \\
CABG alone & $0.59(0.31-1.12)$ & 0.108 \\
Ischemic time $\geq 90 \mathrm{~min}$ & $1.52(1.04-2.22)$ & 0.029 \\
\hline
\end{tabular}

HF NYHA: classification of heart failure New York Heart Association, CABG: coronary artery bypass graft surgery. * Adjusted for IC-NYHA III /IV, CABG, and ischemic time > 90 min: for having multicollinearity with prolonged ischemic time, it was decided not to include in this analysis CPB time >120 min

Table 5. Perioperative complications.

\begin{tabular}{lc}
\hline Complications & $\mathrm{n}=80$ \\
\hline Directly related to the IAB & $4(5.0)$ \\
Lower limb ischemia (\%) & $2(2.5)$ \\
Lower limb amputation (\%) & $1(1.3)$ \\
Rhabdomyolysis (\%) & $1(1.3)$ \\
Aneurysm of the lower limb (\%) & \\
Not directly related to the IAB & $28(35.0)$ \\
Acute renal failure (\%) & $21(26.3)$ \\
Sepsis (\%) & $19(23.8)$ \\
Prolonged mechanical ventilation (\%) & $16(20.0)$ \\
Perioperative myocardial infarction (\%) & $11(13.8)$ \\
Respiratory infection (\%) & $11(13.8)$ \\
PCR reversed & $9(11.3)$ \\
Reoperation for bleeding (\%) & $6(7.5)$ \\
Requiring hemodialysis (\%) & $4(5.0)$ \\
Wound infection in the lower limb (\%) & $2(2.5)$ \\
Hepatic dysfunction (\%) & $4(5.0)$ \\
Other complications (\%) & \\
\hline
\end{tabular}

IAB: IAB, AMI: acute myocardial infarction, PCR: cardiorespiratory arrest only the ischemia time> 90 min was an independent predictor of mortality, with the presence of heart failure NYHA III / IV only tend to be a predictor.

Regarding complications (Table 5), 71.3\% (95\% HF: 61.2 to 81.4 ) of patients had at least one additional complication in the perioperative period. Complications directly attributable to the IABP, the lower limb ischemia were the most described, observed in four $(5.0 \%)$ patients: of these, two required amputation of the lower limb, one of whom had associated rhabdomyolysis.

Following one year of the 37 patients who were discharged from hospital, two had died due to complications of their underlying diseases. Of the 35 remaining patients, $32(91.4 \%)$ completed follow-up of 6 months and $25(71.4 \%)$ to one year, the others being censored (10 patients, $12.5 \%$ of the total sample). Survival at 6 months was $45 \%$, and 1 year, $43.6 \%$, observing a plateau in the survival curve after the initial sharp drop, related to hospital mortality. The survival curve of KaplanMeier method is shown in Figure 1.

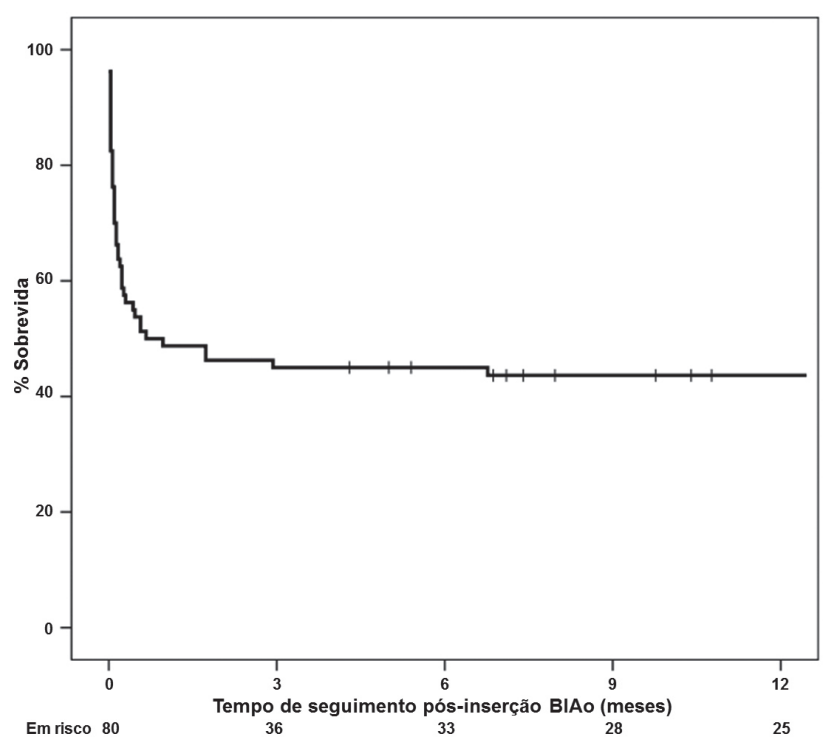

Fig 1 - Survival curve by Kaplan-Meier method

\section{DISCUSSION}

The offered by IABP counterpulsation produces hemodynamic effects that benefit the cardiac significantly as a result of increased myocardial oxygen supply and consequent improvement of diastolic perfusion as well as the reduction in oxygen consumption due to reduced left ventricular afterload [9]. Because of these hemodynamic effects, is ideal application in post-cardiotomy cardiac dysfunction, especially if coronary hypoperfusion is 
suspected, their inclusion should be considered as soon as possible evidence indicating myocardial dysfunction, preferably during surgery, in order to avoid the need for excessive inotropic support [10].

Since its introduction in clinical practice, the IABP has become the most widely used means of mechanical circulatory support [11]. International registry data describe the most common indications for its use are hemodynamic support during or after cardiac catheterization (20.6\%), cardiogenic shock (18.8\%), weaning from CPB (16.1\%), use pre surgery in high risk patients $(13.0 \%)$ and refractory unstable angina (12.3\%) [12].

Patients who develop low cardiac output syndrome have significantly higher prevalence of perioperative myocardial infarction and a higher operative mortality. Thus, the development of this syndrome represents revascularization or inadequate myocardial protection and can act as a marker of perioperative myocardial injury [13]. The distinction between cardiogenic shock and myocardial stunning postoperative transient, as determined in $45 \%$ of elective patients, it is important, since they are associated with different outcomes: only patients with myocardial stunning can generally have quickly suspended his inotropic support [10].

If a reversible myocardial injury occurs during a cardiac surgery, myocardial function can improve the myocardial work is reduced, the main goal of physiological circulatory assist devices [14]. The myocardial stunning is defined as a post-ischemic myocardial dysfunction prolonged, but transient, of a viable myocardium that was recovered by reperfusion, despite the cardioprotection afforded by administration of cold cardioplegia during aortic clamping, this dysfunction is a well recognized sequel of cardiopulmonary prolonged bypass [15]. Several reports have shown depressed ventricular function in the early hours after CABG: the dysfunction usually resolves within 24 to 48 hours and there seems to be dependent on changes in preload, afterload or temperature [16].

The overall mortality of patients requiring IABP in intraand postoperative ranges from $21 \%$ to $73 \%$. The insertion of these periods, as well as the occurrence of cardiogenic shock, has been identified as an independent predictor of mortality [1]. These rates have remained relatively stable over the past 10 years despite improvements in surgical techniques, myocardial protection and medical technology, a fact which is mainly due to increased average age of the patients, the frequency of reoperations and surgery emergency, and the severity of [17]. Complications related to the use of the IAB are frequent, with a reported incidence of $8 \%$ to $18 \%$, and mortality related directly to the device ranged between $0 \%$ and $2.6 \%$ [7].

In one case series published in Brazil, Jucá et al. [17] studied 98 consecutive cases of insertion of the IAB post- cardiac surgery, $8 \%$ describing the complications inherent in the balloon and $40 \%$ of other complications such as pneumonia, renal failure, coagulopathy and neurological diseases, and $44 \%$ of deaths. In the present study, the perioperative complication rate was high, as a major complication directly related to the IAB lower limb ischemia, observed in $5 \%$ of patients.

Several previous studies have focused on identifying prognostic factors for patients treated with the IABP without agreement on preoperative determinants of survival. As a result of the variability in the indications for insertion of the IABP and differences in patient populations, there is great variability in the results reported [18].

The surgery is a major determinant of survival: the largest hospital survival and long-term patients undergoing $\mathrm{CABG}$ receiving IAB, compared with patients undergoing other cardiac surgical procedures, was confirmed by many studies. In a large series of cases, Torchiana et al. [19] demonstrated that the performance of CABG surgery was not associated with twice the risk of mortality. It is clear that patients with ongoing ischemia and shock do better than those with no shock and ischemia: the higher mortality of patients with valvular disease and cardiogenic shock who receive an IABP is a reflection of the fact that the problem of ventricular dysfunction is not reversible or partially reversible. Patients with deep hemodynamic persist after the insertion of the IABP are likely to survive on the use of a ventricular assist device (VAD) [1].

In the present study, the more significant that the surgery was the time of the procedure, and surgery with prolonged ischemia time associated with increased mortality, perhaps related to post-ischemic myocardial stunning cited above. The myocardial protection in all procedures performed in this series was performed using crystalloid cardioplegia St Thomas II, coronary infusion every 30 minutes and maintained hypothermia with saline in the form of shapeless semi-liquid ice in the pericardial cavity during myocardial ischemia.

The lower limb ischemia is the most common complication of the use IAB reported in $8 \%$ to $42 \%$ of cases, this variation is largely dependent on the setting of ischemia and the intensity of observation of the patient. Several studies have examined risk factors for vascular complications, especially, among them women, peripheral vascular disease and diabetes, which have been identified as independent risk factors for vascular complications. Some other studies involve long-standing use of the IABP, smoking and hypertension as risk factors [1].

In a study involving 16,909 patients, 9179 underwent CABG, Ferguson et al. [12] identified the presence of peripheral vascular disease, female sex, body surface area $<1.65 \mathrm{~m} 2$ and age $\geq 75$ years as risk factors for major complications. In this study, this definition included 
increased lower limb ischemia, severe bleeding, balloon leak or death directly attributable to the insertion of the balloon or its failure.

In this study, the occurrence of acute renal failure (ARF) was a complication not directly related to the IAB most common, occurring in $35 \%$ of patients. Brito et al. [20] analyzed factors related to the occurrence of ARF postCABG, observed that the need for IABP was a risk factor, though not independent.

The identification of a subgroup of high risk for low cardiac output optimization can dictate the preoperative use of diuretics, afterload reduction and / or support with IABP [2]. Miceli et al. [21] developed a score to identify high-risk patients and predict the need for insertion of the IAB in patients undergoing CABG. Multivariate analysis identified age over 70 years, degree of ventricular dysfunction, previous cardiac surgery, emergency surgery, injury, TBI, angina CCS III / IV and myocardial infarction as independent risk factors for the need for insertion of the IABP. Similar studies also exist for aortic valve surgery [22] and isolated mitral valve [2]: these scores may help in the planning of subsequent surgery and postoperative management.

The definition of shock continues after cardiotomy variable but generally reflects patients who have inadequate performance after cardiac surgery, although inotropic support with IABP and [23]. Several studies indicate a correlation between hemodynamic parameters and the level of pharmacological support needed: the more inotropic drugs are required to restore hemodynamic stability, the worse the outcome [24]. The identification of the group of patients who are at increased risk of death when inserting IABP will help determine which patients may benefit from a temporary support, beyond what is offered by that device or other management strategies [18]: those patients with low cardiac output syndrome, despite the support of the IABP, the ventricular assist devices (VAD) have been used to achieve recovery of the circulatory system, with variable success, and different intentions. In some patients, this device was used as a bridge to heart transplantation, and in others as permanent replacement therapy [25].

The "IABP score," described by Hausmann et al. [25], proved to be able to estimate survival at 30 days after 1 hour of implantation of the IAB, showing that the rapid recovery of the left ventricle predicts patient survival, suggesting that in individuals with high scores, implantation of a VAD should be considered. The parameters that make up this score are the needs of adrenaline, maximum urine output in diuretic therapy, mixed venous oxygen saturation and left atrial pressure. Another score for the same purpose was proposed by Saeed et al. [26], which, after six hours of implantation of the IABP has the power to predict survival at 30 days from the mean arterial pressure, epinephrine dose, central venous pressure and serum lactate concentration.

In general, patients at risk of low cardiac output has long history of coronary atherosclerosis with previous myocardial infarction resulting in reduced cardiac reserve, has one or more coronary revascularization and unstable, requiring emergency surgery. The incomplete revascularization and perioperative AMIs are common, in fact, previous studies showed that over two thirds of patients who die after the post-cardiotomy support and are subjected to autopsy had evidence of extensive AMI, this information is important because it allows the identification of patients at high perioperative risk, and may be used to select a device intraoperatively [27].

The AMI, trans- and postoperative period, occurs in $5 \%$ to $15 \%$ of CABG. Analysis of autopsies indicate that the majority of grafts were patent, so that the pathophysiological mechanism of perioperative AMI appears to be related to the disproportion between supply and myocardial oxygen consumption, and not with occlusion of saphenous grafts, and supports the idea there may be benefit of prophylactic IAB in CABG [9].

Small randomized trials, such as those conducted by Christenson et al. [28-32] and cohort studies have associated the inclusion of pre-operative IABP with better outcomes in high-risk patients undergoing CABG. The definition of "high risk" varies between these studies and include older age, low ejection fraction or symptomatic congestive heart failure, injury to the ECA, the second CABG surgery or urgent / emergency [11]. In recent Cochrane meta-analysis [33] observed that the evidence suggests that preoperative IABP may have beneficial effect on mortality and morbidity in specific high-risk groups undergoing CABG, however, there are many problems with the quality, reliability and validity of the tests. The available evidence is not robust enough to extend the use of the IABP for elective high-risk patients: define more precisely which groups of patients who may benefit will be the challenge for the future.

Despite over 30 years of clinical use and the large scientific literature on IABP, several critical issues still need to be answered, such as the proper use and great device, its use preoperatively in high risk patients and the role of the IABP for support intra-and postoperatively on the use of VAD [1]. Patients who need the IABP form a group of very high risk for morbidity and mortality. Its use, however, allows recovering many patients from a development which would be invariably fatal.

Patients who require cardiac surgery IABP may have worse outcomes than patients who receive such preoperative circulatory support: in both groups, however, after an early peak in mortality, the midterm results are characterized by a plateau survival rates [11]. Although the early mortality rate in patients who need the IABP is high, the long-term prognosis is relatively good for those who 
survive the immediate postoperative period [18]: patients discharged from hospital seem to have good survival, determined by the underlying disease and comorbidities [1]. The higher mortality rate after hospital discharge occurs during the first year, especially in the first three months after the operation [18.34-36], as also observed in this series.

Patients who need the IABP form a group of very high risk for morbidity and mortality: in the present study, hospital mortality was $53.8 \%$ and the rate of postoperative complications of $71.3 \%$, numbers that corroborate this claim. Using this device, however, allows many patients to recover a development which would invariably fatal, and the patient was discharged a good medium term survival.

\section{REFERENCES}

1. Baskett RJ, Ghali WA, Maitland A, Hirsch GM. The intraaortic balloon pump in cardiac surgery. Ann Thorac Surg. 2002;74(4):1276-87.

2. Maganti M, Badiwala M, Sheikh A, Scully H, Feindel C, David TE, et al. Predictors of low cardiac output syndrome after isolated mitral valve surgery. J Thorac Cardiovasc Surg. 2010;140(4):790-6.

3. Gun C, Piegas LS. Síndrome de baixo débito no pós-operatório de cirurgia cardíaca. Rev SOCESP. 2001;11(5):1023-32.

4. Kantrowitz A, Krakauer JS, Rosenbaum A, Butner AN, Freed PS, Jaron D. Phase-shift balloon pumping in medically refractory cardiogenic shock. Results in 27 patients. Arch Surg. 1969;99(6):739-43.

5. Bregman D, Nichols AB, Weiss MB, Powers ER, Martin EC, Casarella WJ. Percutaneous intraaortic balloon insertion. Am J Cardiol. 1980;46(2):261-4.

6. Fernandes MA. Choque cardiogênico. Suporte mecânico circulatório. Rev SOCERJ. 2001;2(1):45-8.
7. Meharwal ZS, Trehan N. Vascular complications of intra-aortic balloon insertion in patients undergoing coronary revascularization: analysis of 911 cases. Eur J Cardiothorac Surg. 2002;21(4):741-7.

8. Parissis H, Leotsinidis M, Akbar MT, Apostolakis E, Dougenis D. The need for intra aortic balloon pump support following open heart surgery: risk analysis and outcome. J Cardiothorac Surg. 2010;5:20.

9. Kern M, Santanna JRM. O uso do balão intra-aórtico no préoperatório de cirurgia de revascularização miocárdica, associada à disfunção ventricular grave. Arq Bras Cardiol. 2006;86(2):97104.

10. Mebazaa A, Pitsis AA, Rudiger A, Toller W, Longrois D, Ricksten SE, et al. Clinical review: practical recommendations on the management of perioperative heart failure in cardiac surgery. Crit Care. 2010;14(2):201.

11. Dhaliwal AS, Chu D, Huh J, Ghadir M, Sansgiry S, Atluri P, et al. Prognostic impact of intra-aortic balloon pump insertion before versus after cardiac surgical intervention in a veteran population. Am J Surg. 2009;198(5):628-32.

12. Ferguson JJ 3rd, Cohen M, Freedman RJ Jr, Stone GW, Miller MF, Joseph DL, et al. The current practice of intra-aortic balloon counterpulsation: results from the Benchmark Registry. J Am Coll Cardiol. 2001;38(5):1456-62.

13. Rao V, Ivanov J, Weisel RD, Ikonomidis JS, Christakis GT, David TE. Predictors of low cardiac output syndrome after coronary artery bypass. J Thorac Cardiovasc Surg. 1996;112(1):38-51.

14. Hoy FB, Mueller DK, Geiss DM, Munns JR, Bond LM, Linett $\mathrm{CE}$, et al. Bridge to recovery for postcardiotomy failure: is there still a role for centrifugal pumps? Ann Thorac Surg. 2000;70(4):1259-63.

15. Przyklenk K, Aoki A, Bellows S, Klinedinst D, Zubiate P Jr, Hale SL, et al. Stunned myocardium following prolonged cardiopulmonary bypass: effect of warm versus cold cardioplegia in the canine model. J Card Surg. 1994;9(3 Suppl):506-16.

16. Kloner RA, Przyklenk K, Kay GL. Clinical evidence for stunned myocardium after coronary artery bypass surgery. $\mathrm{J}$ Card Surg. 1994;9(3 Suppl):397-402.

17. Jucá FG, Moreira LFP, Carmona MJC, Stolf NAG, Jatene $\mathrm{AD}$. Uso do balão intra-aórtico no choque cardiogênico no pós-operatório de cirurgia cardíaca: análise prospectiva durante 22 meses. Rev Bras Cir Cardiovasc. 1998;13(4):351-3.

18. Arafa OE, Pedersen TH, Svennevig JL, Fosse E, Geiran OR. Intraaortic balloon pump in open heart operations: 10-year follow-up with risk analysis. Ann Thorac Surg. 1998;65(3):741-7. 
19. Torchiana DF, Hirsch G, Buckley MJ, Hahn C, Allyn JW, Akins CW, et al. Intraaortic balloon pumping for cardiac support: trends in practice and outcome, 1968 to 1995. J Thorac Cardiovasc Surg. 1997;113(4):758-64.

20. Brito DJA, Nina VJS, Nina RVAH, Figueiredo Neto JA, Oliveira MIG, Salgado JVL et al. Prevalência e fatores de risco para insuficiência renal aguda no pós-operatório de revascularização do miocárdio. Rev Bras Cir Cardiovasc. 2009;24(3):297-304.

21. Miceli A, Duggan SM, Capoun R, Romeo F, Caputo M, Angelini GD. A clinical score to predict the need for intraaortic balloon pump in patients undergoing coronary artery bypass grafting. Ann Thorac Surg. 2010;90(2):522-6.

22. Maganti MD, Rao V, Borger MA, Ivanov J, David TE. Predictors of low cardiac output syndrome after isolated aortic valve surgery. Circulation. 2005;112(9 Suppl):I448-52.

23. Rao V. Condition critical: can mechanical support prevent death due to postcardiotomy shock? J Card Surg. 2006;21(3):238-9.

24. Hagan K, Casanova-Ghosh E. Postcardiotomy cardiogenic shock: the role of ventricular assist devices. Crit Care Nurs Clin North Am. 2007;19(4):427-43.

25. Hausmann H, Potapov EV, Koster A, Krabatsch T, Stein J, Yeter R, et al. Prognosis after the implantation of an intraaortic balloon pump in cardiac surgery calculated with a new score. Circulation. 2002;106(12 Suppl 1):I203-6.

26. Saeed D, El-Banayosy A, Zittermann A, Fritzsche D, Mirow $\mathrm{N}$, Morshuis M, et al. A risk score to predict 30-day mortality in patients with intra-aortic balloon pump implantation. Thorac Cardiovasc Surg. 2007;55(3):163-7.

27. Smedira NG, Blackstone EH. Postcardiotomy mechanical support: risk factors and outcomes. Ann Thorac Surg. 2001;71(3 Suppl):S60-6.

28. Christenson JT, Licker M, Kalangos A. The role of intra-aortic counterpulsation in high-risk OPCAB surgery: a prospective randomized study. J Card Surg. 2003;18(4):286-94.
29. Christenson JT, Simonet F, Badel P, Schmuziger M. Optimal timing of preoperative intraaortic balloon pump support in high-risk coronary patients. Ann Thorac Surg. 1999;68(3):934-9.

30. Christenson JT, Badel P, Simonet F, Schmuziger M. Preoperative intraaortic balloon pump enhances cardiac performance and improves the outcome of redo CABG. Ann Thorac Surg. 1997;64(5):1237-44.

31. Christenson JT, Simonet F, Badel P, Schmuziger M. Evaluation of preoperative intra-aortic balloon pump support in high risk coronary patients. Eur J Cardiothorac Surg. 1997;11(6):1097-103.

32. Christenson JT, Simonet F, Badel P, Schmuziger M. The effect of preoperative intra-aortic balloon pump support in patients with coronary artery disease, poor left-ventricular function (LVEF < 40\%), and hypertensive LV hypertrophy. Thorac Cardiovasc Surg. 1997;45(2):60-4.

33. Theologou T, Bashir M, Rengarajan A, Khan O, Spyt T, Richens D, et al. Preoperative intra aortic balloon pumps in patients undergoing coronary artery bypass grafting. Cochrane Database Syst Rev. 2011;(1):CD004472.

34. Mejía OAV, Lisboa LAF, Tiveron MG, Santiago JAD, Tineli RA, Dallan LAO, et al. Cirurgia de revascularização miocárdica na fase aguda do infarto: análise dos fatores preditores de mortalidade intra-hospitalar. Rev Bras Cir Cardiovasc. 2012;27(1):66-74.

35. Anderson AJPG, Barros Neto FXR, Costa MA, Dantas LD, Hueb AC, Prata MF. Preditores de mortalidade em pacientes acima de 70 anos na revascularização miocárdica ou troca valvar com circulação extracorpórea. Rev Bras Cir Cardiovasc. 2011;26(1):69-75.

36. Oliveira EL, Westphal GA, Mastroeni MF. Características clínico-demográficas de pacientes submetidos a cirurgia de revascularização do miocárdio e sua relação com a mortalidade. Rev Bras Cir Cardiovasc. 2012;27(1):52-60. 